\title{
A study on Inclusive Finance and Enterprise Environmental Investment Single-variable test based on bivariate mechanism
}

\author{
Zheng Fei ${ }^{1, a}$, Liu Han ${ }^{1}$, Li Teng ${ }^{1}$, Qiu Peipei ${ }^{1}$ \\ ${ }^{1}$ Henan University of Economics\&Law, School of Accounting, Zhengzhou, China
}

\begin{abstract}
The deep integration of digital technology and finance is driving a rapid transformation of financial services in China. Inclusive Finance, different from traditional finance, how to play the role of "inclusive" on environmental decision-making to promote the national environmental protection work? There is little literature to inquire the role of Inclusive Finance at the micro level. This paper discusses the impact of inclusive finance on enterprise environmental protection investment and its conduction mechanism. The study found that inclusive finance could drive enterprise environmental investment. In particular, the usage depth of inclusive finance has a sustainable effect on the promotion of environmental protection investment. Furthermore, the empirical test of the mechanism shows that inclusive finance can break through the mismatch problems of traditional finance and display a better "inclusive" feature to ease the credit constraints and enhance their ability of technological innovation, which help enterprise to invest in environmental protection. Based on our findings, we provide empirical evidence and policy options for the optimization of inclusive finance to help environment protection.
\end{abstract}

\section{Introduction}

The rapid economic growth over the past forty years has caused increasingly prominent environmental problems. China's Environmental Performance Index ranking 120th out of 180 countries, according to the Environmental Performance Index: 2018 report. "Lucid waters and lush mountains are invaluable assets". Entrepreneurship is essential for conservation. considering the public goods of natural resources, the negative externality of environmental pollution and the rational assumption of "economic being", it' a difficult task to green production for entrepreneurship. What's more, the environmental protection investment has strong externality, large investment, long cycle, slow effect and high risk. There exists the problem of high adjustment cost and financing cost. Among these factors, the availability and sufficient funding is the most important element. As an important part of the real economy, technological innovation will not only lead to productivity gains, but mode of production "green" revolution will reduce environmental pollution. Inclusive finance, a blend of big data and emerging technologies, promises to break the logjam and set the stage for enterprise environmental activism. "Inclusive Finance", a shared, convenient, low-cost, digital financial platform benefits groups excluded from traditional finance and traditional credit reporting, whether this financial model could drive environmental investment through refined risk pricing, precise user portraits and intensive business processes has become a practical problem worth exploring.

We attempt to contribute the following: Firstly, from the micro-level to verify the relationship "inclusive financial-corporate environmental investment". Second, based on "financial constraints", "Technology R\&D" and other differential identification tests, it is widely accepted to clarify the mechanisms about financing innovation and environmental investment. Thirdly, heterogeneity of property rights, different regions and industrial life cycle explore the differences in driving effect of inclusive finance on environmental investment. The discussions not only improve the effectiveness and scientific of financial inclusion support to the national environmental protection work, but also an empirical evidence for the further development of inclusive growth in China.

\section{Literature Review}

Environmental investment can promote the sustainable development of enterprises and effectively drive economic transformation, which will help to achieve green development. There is a wealth of research on which factors drive the micro-entities to invest in environmental protection, they are divided into approximately four parts: The government literature mainly from environmental regulation, environmental subsidies and so on.

Inclusive finance, combining the advantages of traditional and internet finance, is a financial system characterized by modernization. Current literature on

a598327225@qq.com 
inclusive finance focuses on how digital finance affects TFP growth rates, innovation and entrepreneurship, financial demand, and economic growth. It was the first study to link digital finance to inclusive growth in household income. Li Et Al. (2020) point out the impact of digital finance on inclusive growth driven by the Internet revolution and digital economy in China, which fills the gap in the research on the impact of digital economy and finance on income distribution. Karlan et Al (2019) synthesized the financial inclusion index for families, and empirically examined the development of financial inclusion for families from a micro-family perspective.

Previous studies have provided a powerful theoretical support and method inspiration for this paper to explore a series of issues triggered by "inclusive finance enterprise environmental investment", there is still a lack of a complete analytical framework and empirical research on the inclusive financial driving mechanism. More importantly, the current study of inclusive financial measurement and economic consequences more focused on the national (regional) level, rarely extend to the microenterprise level. To what extent have enterprises enjoyed the fruits of inclusive financial development? How does inclusive finance affect environmental investment at the micro level? This paper has practical value and enlightening significance for the study of inclusive driving effect on environmental investment from micro perspective.

\section{Research Design}

\subsection{Sample Selection and Data Sources}

We choose listed companies that disclose the amount of environmental investment from 2011 to 2018 as the research object, data from CSMAR and Recci. A panel data set is constructed by matching the index of digital financial inclusion is the product of a joint project by the Institute of Digital Finance (at Peking University) and Ant Financial.

\subsection{Setting of Variables}

Explained variable: Environmental Investment (IEC). IEC is the natural logarithm of the absolute amount of environmental investment.

Core explanatory variables: Inclusive Finance (DIF). Index of Digital Financial Inclusion as the proxy variable to measure the development degree of digital finance at the provincial level (excluding Hong Kong, Macao and Taiwan) in China.

Medium conduction variable. Financial constrains (SA-Index): The measurement algorithm of financing constraint is SA index, and the larger the absolute value of SA index is, the higher the financing constraint is. technological Innovation (LNPAT). The measurement of technological innovation is the natural logarithm of the number of invention patents application.

\subsection{Model Setting}

$$
\begin{aligned}
& \text { Ie } c_{i, t}=\alpha_{0}+\alpha_{1} \text { DIF }_{i, t}+\alpha_{2} \text { Age }_{i, t}+\alpha_{3} \text { LeV }_{i, t}+\alpha_{1} \text { Tobing }_{i, t}+\alpha_{5} \text { Roa }_{i, t} \\
& +\alpha_{6} \text { Flow }_{i, t}+\alpha_{7} \text { Frist }_{i, t}+\alpha_{8} \text { Cash }_{i, t}+\alpha_{9} \text { Size }_{i, t}+\alpha_{10} \operatorname{Cos} t_{i, t} \\
& +\sum \text { Year }+\sum \text { Ind }+\varepsilon
\end{aligned}
$$

\section{Analysis and Implementation}

\subsection{Regressions of inclusive finance and environmental investment}

Table 1 gives an empirical test on the relationship between "inclusive finance and the environmental Investment". As expected, the regression coefficients were all positive and significant at the level of $5 \%$, which indicated that inclusive finance was helpful to enhance the level of environmental investment. Inclusive finance has overcome the shortcomings of traditional finance in terms of financing by using technologies such as big data and blockchain, effectively improving the circulation efficiency of the elements in the financial system, and enriching the financing channels of enterprises, which is better to serve the enterprise capital needs, thus enhancing the enterprise investment.

Table1: regressions of inclusive finance and environmental investment

\begin{tabular}{lllll}
\hline & $(1)$ & $(2)$ & $(3)$ & $(4)$ \\
& IEC & IEC & $\begin{array}{l}\text { IEC } \\
\text { Random } \\
\text { Effect }\end{array}$ & $\begin{array}{l}\text { IEC } \\
\text { Fixed } \\
\text { Effect }\end{array}$ \\
& & & & \\
& & & & \\
DIF & $0.004^{* * *}$ & $0.003^{* *}$ & $0.005^{* * *}$ & $0.010^{* * *}$ \\
& $(2.59)$ & $(2.41)$ & $(2.81)$ & $(2.95)$ \\
& $(-4.60)$ & $(-5.68)$ & $(-1.39)$ & $(-1.61)$ \\
lev & & $-0.050^{* * *}$ & -0.008 & -0.001 \\
& & $(-3.31)$ & $(-0.79)$ & $(-0.14)$ \\
flow & & $2.715^{* * *}$ & 0.384 & -0.068 \\
& & $(6.48)$ & $(1.36)$ & $(-0.23)$ \\
cost & & $0.456^{*}$ & -0.004 & 0.143 \\
& & $(1.74)$ & $(-0.02)$ & $(0.59)$ \\
Largest & & $0.005^{* *}$ & $0.007^{* * *}$ & $0.006^{*}$ \\
Holder & & & & \\
& & $(2.31)$ & $(2.89)$ & $(1.82)$ \\
size & & $0.877^{* * *}$ & $0.665^{* * *}$ & $0.399^{* * *}$ \\
& & $(30.10)$ & $(17.61)$ & $(7.18)$ \\
cons & $14.626^{* * *}$ & $-4.445^{* * *}$ & -0.328 & $13.249^{* * *}$ \\
& $(60.00)$ & $(-6.38)$ & $(-0.36)$ & $(5.48)$ \\
\hline$N$ & 2837 & 2837 & 2837 & 2837 \\
\hline
\end{tabular}

\subsection{Reducing Dimension}

To give a more accurate picture of inclusive finance impact on environmental activities, we use the second dimension of the financial inclusion index, the development indices of coverage breadth, usage depth, and payment to describe the impact on the environmental investment respectively. What is it about the breadth of participation, the depth of use, or the support of digital services that affects financial services to promote green 
investment? The empirical results in Table 3 can answer this question. The table shows the influence of the development degree of "breadth-depth-service support" on the environmental investment level, breadth index has no significant influence on the environmental investment, in contrast, depth index and digital service support significantly drive the environmental investment (with a positive coefficient and a statistical significance test of 1\%). The empirical test in Table 3 sends an interesting message: The further development of inclusive finance must be supported by Usage depth and digital services. Coverage that cannot help enterprise at the micro level, this also points the way for the follow-up development of inclusive finance in China.

Table 2: Inclusive finance and environmental investment: reducing dimension

\begin{tabular}{llll}
\hline & $(1)$ & $(2)$ & $(3)$ \\
& IEC & IEC & IEC \\
\hline $\begin{array}{l}\text { Coverage } \\
\text { breadth }\end{array}$ & $0.002^{*}$ & & \\
& & & \\
Usage_depth & $(1.69)$ & & \\
& & $0.003^{* * *}$ & \\
payment & & $(3.71)$ & \\
& & & $0.003^{* * *}$ \\
$N N$ & 2837 & 2837 & 2837 \\
$\mathrm{~F}$ & 37.040 & 37.370 & 37.286 \\
\hline
\end{tabular}

\subsection{Robust Testing}

We use the method of eliminating special samples and instrumental variable to test the robust of the model. We removed the impact of the 2015 stock market disaster in China. Network penetration rate of each province (data from "China Internet Development Statistical Report on Development Status) as an instrumental variable for endogeneity. The conclusion is robust.

\section{The Mechanism Test}

A study on the conduction mechanism selects the Financing Constraints and technological R\&D. There are two main considerations in selecting them. First, efficient and low-cost financial support is the core element of environmental investment with high quality and efficiency. Inclusive growth has widened the financing channels of enterprises, made the enterprises that are limited by the insufficient money held and restricted the ability of environmental investment to devote to environmental protection investment. Second, following this logic, inclusive finance alleviates credit constraints, solves the problem of "financing difficulty" and "high financing cost", and then uses the funds to develop R\&D, which is an important prerequisite for achieving technological progress. In the sample environment, this paper examines the impact of inclusive finance on $R \& D$ Investment and innovation performance (using the number of patents granted as a measure of innovation performance), explained variable and the core explanatory variable are treated with logarithm. In Table 3, inclusive finance regression coefficient to the $\mathrm{SA}$ index is significantly negative and highly significant, which means that digital finance greatly alleviates financing constraints.

Table 3: Mechanism of Inclusive Finance's Influence on Environmental Protection Investment

\begin{tabular}{|c|c|c|c|}
\hline \multicolumn{4}{|c|}{ Path 1: Financial constrains } \\
\hline \multirow{3}{*}{ DIF } & IEC & SA & IEC \\
\hline & $0.0033^{* *}$ & $-0.0004^{* * *}$ & $0.0025^{*}$ \\
\hline & $(2.43)$ & $(-4.42)$ & $(1.82)$ \\
\hline \multirow[t]{2}{*}{ SA } & & & $-2.4548^{* * *}$ \\
\hline & & & $(-7.59)$ \\
\hline \multirow[t]{3}{*}{$\mathrm{F}$} & 16.7062 & 252.5733 & 17.7350 \\
\hline & Technolo & ical innovat & \\
\hline & IEC & LNPAT & IEC \\
\hline \multirow[t]{2}{*}{ DIF } & $0.0029 * *$ & $0.0072 * * *$ & $0.0032 * * *$ \\
\hline & $(2.41)$ & $(7.39)$ & $(2.68)$ \\
\hline \multirow[t]{2}{*}{ LNPAT } & & & $-0.0497 * *$ \\
\hline & & & $(-2.12)$ \\
\hline $\mathrm{N}$ & 2837 & 2837 & 2837 \\
\hline
\end{tabular}

The empirical results in Table 4 show that inclusive growth provides the impetus for technological innovation activities. This means that enterprise funds are released, sufficient funds within the company can provide support for clean technology R\&D activities, thus driving the enterprise willingness to invest in environmental protection. Following this logic, inclusive finance eased the financing constraints, thereby created more relaxed conditions for its own technology R\&D activities, saved energy and reducing emissions, which injects vitality into enterprise environmental investment. Thus, it forms a positive transmission path of "inclusive finance- ease the financing constraint - promote the progress of clean technology -enhance the level of environmental investment".

Table 4: Single-variable test based on Bivariate Mechanism

\begin{tabular}{|l|l|l|l|l|l|}
\hline \multicolumn{6}{|c|}{ Environmental investment and financial constrains } \\
\hline Variables & Low & & High & & \\
\hline & G1(0) & & G2(1) & & MeanDiff \\
& & Mean1 & & Mean2 & \\
\hline IEC & 1410 & 14.548 & 1427 & 14.811 & $-0.263^{* * *}$ \\
\hline \multicolumn{6}{|c|}{ Environmental investment and technological innovation } \\
\hline IEC & 1432 & 14.623 & 1405 & & $-0.115^{*}$ \\
& & & & 14.738 & \\
\hline
\end{tabular}

\section{Conclusions}

In recent years, the emerging inclusive financial system is merging with the traditional financial system, and the new financial service mode has exerted an important influence on the transition and high-quality development of the Chinese economy. Unlike traditional financial credit, and different from the World Bank's "inclusive finance" calls for countries that need pay more attention to equity and income distribution. The empirical test of the impact, mechanism of inclusive finance on enterprise 
environmental investment has mainly resulted in the following conclusions: First, the inclusive growth has been a significant driver of environmental investment, particularly in the case of deep index and support services. Second, the development of inclusive finance has solved the problems of property right, industry attribute and industry growth cycle bias existing in traditional finance, which can support enterprises environmental investment activities more directionally. Third, inclusive growth can effectively alleviate problems of financing difficulty and high financing cost, driving enterprises to carry out clean technological R\&D.

\section{Recommendation}

Based on our findings, we suggest: First, we should support the deep integration of technology and inclusive finance, under the premise of controlling risks, it is widely accepted that break the isolated island of information, make resources flow, and actively promote high-end technologies such as big data, blockchain, which will lay a solid foundation for inclusive finance activities. At the same time, in order to give full play to the positive role of financial inclusion in driving enterprises to intensify their efforts in pollution control, it is necessary to facilitate enterprises to obtain more convenient and efficient financial services, and to empower enterprises to provide a sound institutional environment for environmental investment activities, providing the impetus for "Green China" by inclusive Finance. Second, China's traditional financial institutions should join hands with inclusive to make financial resources serve enterprises more comprehensively and accurately, provide adequate financial support to enterprises with financing needs and excellent technological R\&D capabilities. Third, we will encourage relevant enterprises to conduct joint research and development of clean technologies with high technological requirements, large-scale investment and long effective cycle, then give full play to the spillover effects of clean technologies to win the battle of pollution prevention and control at an early date.

\section{References}

1. Karlan D S, Kendall J, Mann R, et al., (2019). Research and Impacts of Digital Financial Services[J]. Financial Market Research.

2. Li J, Wu Y, Xiao J J, (2020). The impact of digital finance on household consumption: Evidence from China[J]. Economic Modelling, 86, pp.317-326.

3. Guo, F.,j.Wang,T.kong,X.Zhang and Z.Cheng,(2019).Measuring Chinas Digital Inclusive Financial Development: Index Compilation and Spatial Features.[J].Economics (quarterly) , 04, pp.262-279.

4. Li.T., Xu.X., Su.S., (2016). Inclusive Finance and Economic Growth[J]. Finance Research, 04 pp.5-20.

5. Tang. Guoping et.al, (2013). Environmental Regulation, Industry Attributes and Corporate Environmental investment [J]. Accounting Research ,06, pp.85-98.

6. Tang. Song et.al, (2020). Digital Finance and Enterprise Technology Innovation: Structural Feature, Mechanism Identification and Effect Difference under financial supervision[J] Management of The World, 05,pp.72-86.

7. Wang.Y,Li Y X, Ma Z, Song J B,(2017) Media Coverage, Environmental Regulation and Corporate Environmental Behavior[J]. Nankai Management Review, 06, pp.85-96.

8. Yu. Minggui et.al, (2016). Chinese Industrial Policy and Corporate Technology Innovation [J]. China Industrial Economy, 12, pp.7-24.

9. Zhang Xun et al., (2019). Digital Economy, Financial Inclusion and Inclusive Growth[J]. Economic Research Journal, 08, pp.73-88. 